Bài báo khoa học

\title{
Nghiên cứu tính toán chỉ số đánh giá tài nguyên nước mặt phục vụ cảnh báo, dự báo tài nguyên nước: Thí điểm lưu vực sông Srê Pốk
}

\author{
Lê Thị Mai Vân ${ }^{*}$, Bùi Thị Bích Ngọc ${ }^{1}$, Đoàn Quang Trí ${ }^{2}$, Trương Văn Hùng ${ }^{1}$, Lê Thế \\ Trung ${ }^{1}$
}

${ }^{1}$ Trung tâm Cảnh báo và Dự báo tài nguyên nước; lethimaivantnn@gmail.com; bichngoc209hunre@gmail.com; truongvanhung888@gmail.com; lethetrung.tnmt@gmail.com

${ }^{2}$ Tạp chí Khí tượng Thủy văn, Tổng cục Khí tượng Thủy văn; doanquangtrikttv@gmail.com

*Tác giả liên hệ: lethimaivantnn@gmail.com; Tel: +84-982420298

Ban Biên tập nhận bài: 05/05/2021; Ngày phản biện xong: 15/07/2021; Ngày đăng bài: $25 / 09 / 2021$

Tóm tắt: Đánh giá số lượng, chất lượng nhằm đưa ra dự báo, cảnh báo nguy cơ thiếu hụt và suy giảm tài nguyên nước là vấn đề cấp thiết được đặt ra hiện nay. Nghiên cứu này áp dụng một số phương pháp tính toán các chỉ số đánh giá tài nguyên nước mặt: chỉ số đánh giá số lượng và chỉ số đánh giá chất lượng nước mặt cho lưu vực sông Srê Pốk. Kết quả tính toán thử nghiệm các chỉ số đánh giá tài nguyên nước mặt trên lưu vực sông Srê Pốk tháng $12 / 2020$ cho thấy trong 9 tiểu vùng có chỉ số căng thẳng thấp, có 01 tiểu vùng ở mức căng thẳng trung bình, chất lượng nước tháng $1 / 2021$ tính theo chỉ số WQI cho thấy chất lượng nước sông Srê Pốk rất tốt có thể sử dụng cho mục đích cấp nước sinh hoạt, chất lượng nước tháng 3 có thể sử dụng cho mục đích cấp nước sinh hoạt nhưng cần các biện pháp xử lý phù hợp. Tuy nhiên, tháng $2 / 2021 \mathrm{WQI}$ kém chỉ sử dụng được cho giao thông thủy và các mục đích tương đương khác. Bộ chỉ số được áp dụng tính toán đánh giá tài nguyên nước mặt phục vụ công tác cảnh báo, dự báo tài nguyên nước cho các cấp quản lý và nâng cao tính thực tiễn của bản tin cảnh báo, dự báo đến các đối tượng sử dụng.

Từ khóa: Chỉ số đánh giá tài nguyên nước; Căng thẳng; Bản tin; Srê Pốk.

\section{1. Đặt vấn đề}

Trong bối cảnh hiện nay, sự phát triển dân số cùng với các nhu cầu sử dụng nước phục vụ các hoạt động dân sinh kinh tế gia tăng nhanh chóng, mặt khác tài nguyên nước không phải là vô hạn và có nguy cơ trở nên khan hiếm. Thực tế, ở nước ta việc khai thác, sử dụng và phân bổ nguồn nước đã và đang được thực hiện trên nhiều lưu vực sông đặc biệt là trên các lưu vực sông có tình hình kinh tế phát triển mạnh [1-3]. Tuy nhiên, với nhu cầu sử dụng nước tăng cao, gây tranh chấp giữa các ngành sử dụng nước dẫn đến tình trạng khai thác quá mức nguồn nước tại các lưu vực sông gây ra nguy cơ cạn kiệt, thiếu nước đặc biệt là vào mùa khô. Ngoài ra, biến đổi khí hậu toàn cầu dang diễn ra mạnh mẽ đã tác động tới các thủy hệ, làm tăng thêm sự thay đổi phức tạp và nghiêm trọng liên quan tới nguồn nước, trong những năm gần đây việc tính toán cảnh báo, dự báo tài nguyên nước là mối quan tâm lớn từ cấp quản lý đến các đối tượng sử dụng tài nguyên nước [4-6]. Nhằm đưa ra cái nhìn tổng quan về tài nguyên nước, hỗ trợ ra quyết định cho các cấp quản lý cần nghiên cứu tính toán các chỉ số đánh giá tài nguyên nước về cả số lượng và chất lượng. 
Một số nước trên thế giới hiện nay đã và đang sử dụng các chỉ số đánh giá tài nguyên nước phù hợp với điều kiện phát triển và yêu cầu phát triển cụ thể của từng nước để đánh giá khả năng nguồn nước của các lưu vực sông [7-12]. Ở Việt Nam trong một số báo cáo như Đánh giá tồng quan ngành nước, Chiến lược Quốc Gia về tài nguyên nước có đưa ra các chỉ số đánh giá tài nguyên nước mặt. Về tổng quan cho thấy chưa có nhiều nghiên cứu về chỉ số đánh giá tài nguyên nước về cả số lượng và chất lượng được thực hiện. Trong đó, nghiên cứu [13] đã đưa ra một số phương pháp xác định chỉ số căng thẳng tài nguyên nước và bước đầu áp dụng cho vùng Nam trung bộ, nghiên cứu [14] đã tiến hành đánh giá mức độ căng thẳng nguồn nước lưu vực sông Mã, nghiên cứu [15] đã đề xuất các chỉ số tài nguyên nước mặt và tính toán thí điểm cho lưu vực sông Vệ. Phần mềm tính toán chỉ số chất lượng nước cho lưu vực sông Srê Pốk được đưa ra trong nghiên cứu [16], tuy nhiên kết quả nghiên cứu chỉ dừng lại ở bước xây dựng phần mềm tính toán.

Sông Srê Pốk là một trong những sông nhánh chính của sông Mê Kông, bắt nguồn từ các vùng núi phía Bắc, Đông Bắc và Đông của tỉnh Đắc Lắk, có độ cao từ $800-2.000 \mathrm{~m}$. Trước khi đổ vào sông Mê Kông, sông Srê Pốk nhận thêm nguồn nước rất lớn từ sông Sê San và sông Sê Kong, vị trí điểm nhập lưu với sông Mê Kông ở ngay sát thành phố Stung Treng - Vương quốc Campuchia. Như vậy, đây là lưu vực sông (LVS) liên tỉnh, liên quốc gia nắm vị trí quan trọng trong vấn đề an ninh nguồn nước quốc gia và quốc tế cho nên cần thực hiện tốt công tác quản lý, khai thác bền vững tài nguyên nước trong khu vực, đảm bảo quyền lợi và công bằng giữa các bên liên quan.

Hiện nay các nghiên cứu đã đưa ra các chỉ số đánh giá tài nguyên nước mặt và tính toán thử nghiệm cho các vùng cụ thể, tuy nhiên chỉ mới đánh giá về mặt số lượng. Mục đích nghiên cứu này sẽ tiến hành đánh giá căng thẳng tài nguyên nước về cả số lượng và chất lượng, kết quả nghiên cứu sẽ góp phần hoàn thiện quy định kỹ thuật về cảnh báo, dự báo tài nguyên nước nói chung và tài nguyên nước mặt nói riêng, hỗ trợ ra quyết định cho các cấp quản lý, đảm bảo quyền lợi cho các đối tượng, hộ dùng nước.

\section{Phương pháp nghiên cứu và thu thập số liệu}

\subsection{Giới thiệu khu vục nghiên cưu}

Lưu vực sông Srê Pốk phía Bắc giáp với lưu vực sông Sêsan, phía Nam giáp lưu vực sông Đồng Nai, phía Tây là đường phân lưu của sông Mê Kông, phía Đông giáp lưu vực sông Srê Pốk. Sông Srê Pốk là nhánh sông cấp I của sông quốc tế Mê Kông. Sông Srê Pốk chảy qua 4 tỉnh Đăk Lăk, Đăk Nông, Gia Lai và Lâm Đồng của Việt Nam rồi chảy sang Campuchia nhập lưu với sông Mê Kông ở Stung Treng. Sông Srê Pốk có 41 nhánh cấp I, hầu hết bắt nguồn từ các vùng núi phía Đông Bắc, Đông và đông nam của tỉnh Đăk Lăk, tức là từ các vùng núi bên sườn Đông của dãy Trường Sơn, có độ cao từ 800-2.000 $\mathrm{m}$. Sông suối trong lưu vực phân bố theo hình nan quạt, mở rộng ở thượng và trung lưu, thu hẹp ở hạ lưu. Vị trí địa lý tự nhiên của lưu vực Srê Pốk nằm trong phạm vi 107³0' đến $108^{\circ} 45^{\prime}$ ' kinh độ Đông và $11^{\circ} 53^{\prime}$ ' đến $13^{\circ} 55^{\prime}$ vĩ độ Bắc. Với tổng diện tích tự nhiên là $30.100 \mathrm{~km}^{2}$, thuộc lãnh thổ Việt Nam là hơn $18.200 \mathrm{~km}^{2}$ được chia ra làm hai lưu vực độc lập nhau là lưu vực thượng Srể Pốk có diện tích là $12.527 \mathrm{~km}^{2}$ với $11.200 \mathrm{~km}^{2}$ thuộc tỉnh Đăk Lăk và lưu vực suối Ia Đrăng-Ea Lôp-Ea H’Leo có diện tích là 5.737 km² [17].

Dòng chính sông Srê Pốk có tổng lượng dòng chảy năm đạt 18,4 tỷ $\mathrm{m}^{3}$ (chuỗi dữ liệu 1980-2017). Lưu vực sông Srê Pốk có tổng lượng nước trong mùa khô đạt 3.312,3 triệu m³ chiếm $18,01 \%$ và trong mùa mưa đạt $15.083,79$ triệu $\mathrm{m}^{3}$, chiếm $81,99 \%$ tổng lưu lượng hàng năm. Nhìn chung, trong 16 tiểu lưu vực, tiểu lưu vực Thượng Ea Krông Nô có lượng nước lớn nhất, tiểu lưu vực Hạ Ea Krông Nô là hai lưu vực có lượng nước thấp nhất [17]. 


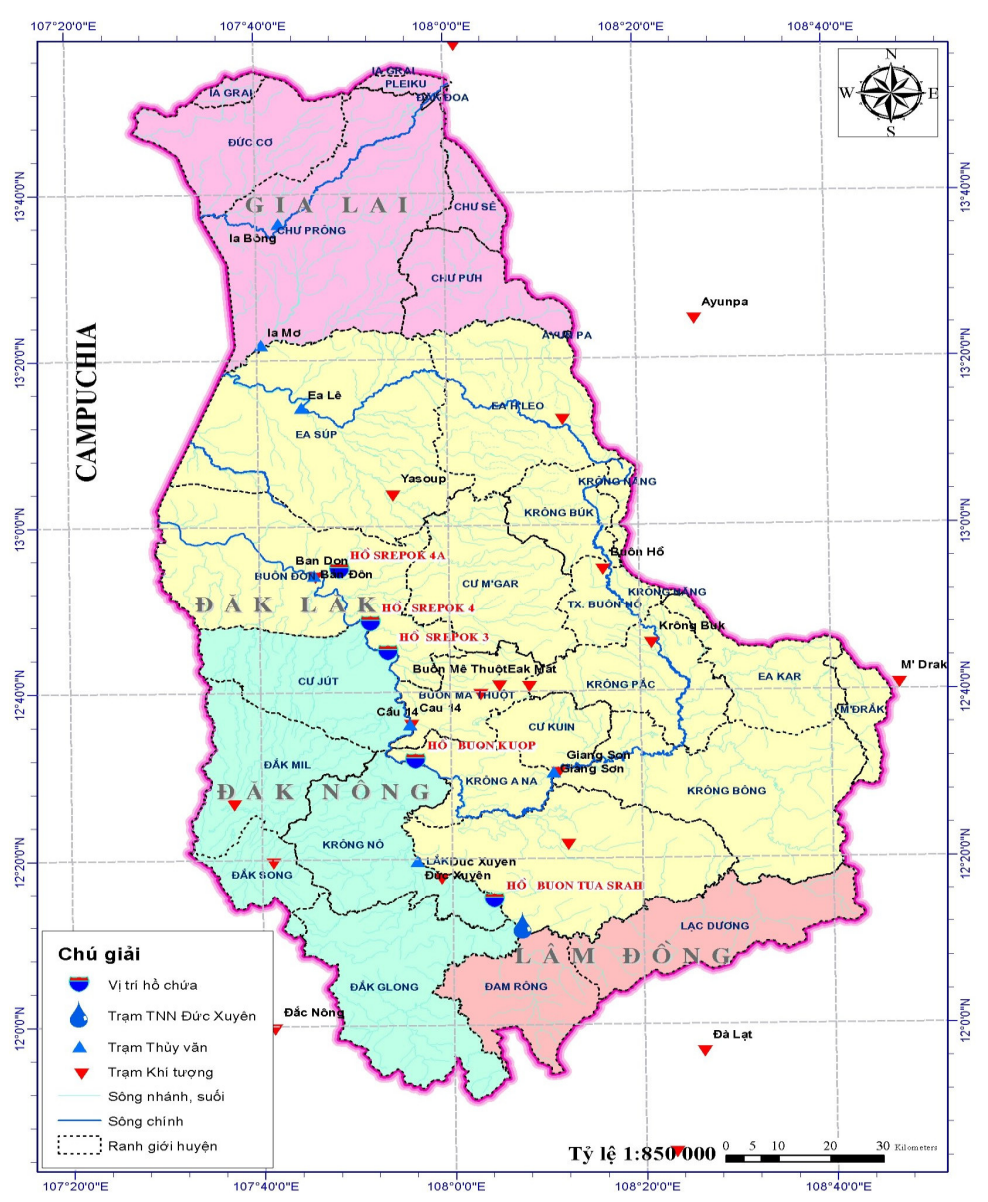

Hình 1. Bản đồ lưu vực sông Srê Pốk.

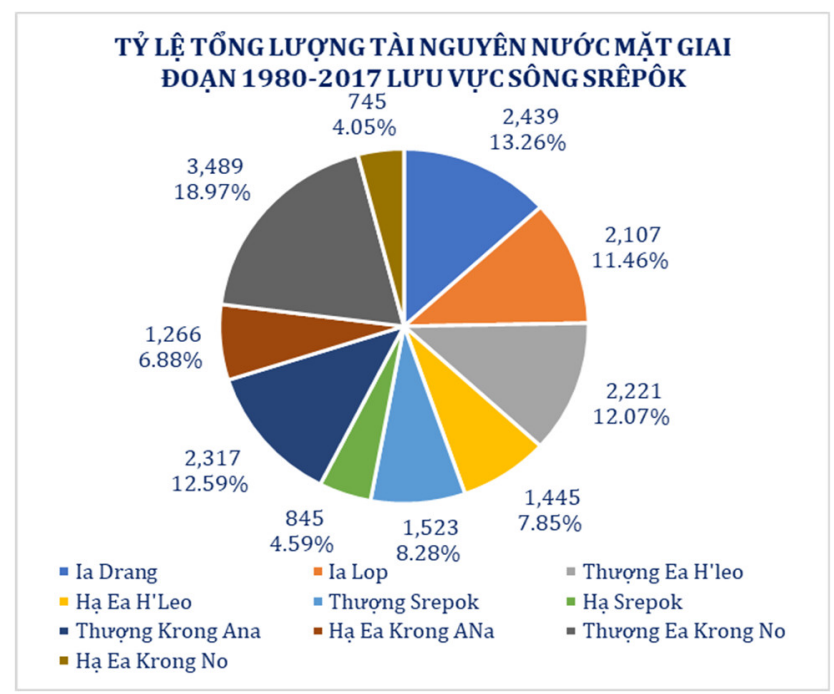

Hình 2. Tỷ lệ tài nguyên nước mặt trung bình năm trên lưu vực sông Srê Pốk.

Hiện trạng khai thác sử dụng tài nguyên nước mặt cụ thể với các ngành trên lưu vực sông Srê Pốk được thống kê như sau: nước mặt được khai thác để cung cấp nước đô thị trong lưu vực Srê Pốk gồm 9 công trình với tổng lưu lượng khai thác là $23,100 \mathrm{~m}^{3} / \mathrm{ngày}$. Số lượng công trình cấp nước nhỏ hàng ngày bao gồm 88.760 công trình. Tổng số khu công nghiệp và cụm công nghiệp sử dụng nguồn nước mặt với quy mô 191 hecta, tổng lượng nước sử dụng là $7.640 \mathrm{~m}$ 3/ngày. Trên lưu vực Srê Pốk, tổng số lượng hồ chứa là 890 hồ, trong đó có 128 hồ trên 3 triệu $\mathrm{m}^{3}, 196$ hồ trên 0.5 triệu $\mathrm{m}^{3}$ và 566 hồ nhỏ. Tổng diện tích tưới trên lưu vực sông Srê Pốk là 119.023,53 hecta. Trên lưu vực sông Srê Pốk có 5 nhà máy thuỷ điện thuộc quy 
trình vận hành liên hồ chứa theo Quyết định 1201 và 55 nhà máy thủy điện vừa và nhỏ, tổng công suất lắp máy $1.170,32 \mathrm{MW}$. Trong đó có 5 nhà máy thuỷ điện thuộc quy trình vận hành liên hồ chứa với tổng công suất $950 \mathrm{MW}, 55$ nhà máy thuỷ điện vừa và nhỏ có tổng công suất 212,93 MW. Trên cơ sở phân tích đặc điểm và hiện trạng các công trình khai thác tài nguyên nước, lưu vực sông Srê Pốk được phân chia thành 10 tiểu vùng dự báo được thể hiện trên Bảng 1.

Bảng 1. Phân chia tiểu vùng dự báo trên lưu vực sông Srê Pốk.

\begin{tabular}{|c|c|c|c|c|c|c|c|}
\hline TT & Tiểu vùng dự báo & $\begin{array}{l}\text { Tiểu lưu } \\
\text { vực sông }\end{array}$ & $\begin{array}{c}\text { Diện tích } \\
\left(\mathrm{km}^{2}\right)\end{array}$ & TT & Tiểu vùng dự báo & $\begin{array}{c}\text { Tiểu lưu vực } \\
\text { sông } \\
\end{array}$ & Diện tích $\left(\mathbf{k m}^{2}\right)$ \\
\hline \multirow[t]{2}{*}{1} & Ia Drang & 1 & 584,3 & & & 36 & 42,1 \\
\hline & & 2 & 382,3 & & & 38 & 9,7 \\
\hline \multirow[t]{5}{*}{2} & Ia Lop & 1 & 19,3 & & & 39 & 508,7 \\
\hline & & 2 & 21,5 & 7 & Thượng Ea Krong & 18 & 11 \\
\hline & & 3 & 904,8 & & No & 25 & 26,5 \\
\hline & & 9 & 744,4 & & & 26 & 638,6 \\
\hline & & 58 & 67,5 & & & 27 & 141,3 \\
\hline \multirow[t]{5}{*}{3} & Thượng Ea H'leo & 4 & 1041,7 & & & 28 & 102,6 \\
\hline & & 5 & 601,7 & & & 29 & 46,4 \\
\hline & & 6 & 465,1 & & & 30 & 1024,7 \\
\hline & & 7 & 54 & & & 31 & 352,5 \\
\hline & & 8 & 336,3 & & & 32 & 317,5 \\
\hline \multirow[t]{3}{*}{4} & Hạ Ea H'Leo & 8 & 383,1 & & & 33 & 250,9 \\
\hline & & 9 & 18,6 & & & 34 & 8,8 \\
\hline & & 58 & 344,7 & 8 & Hạ Ea Krong No & 37 & 866,6 \\
\hline \multirow[t]{12}{*}{5} & Thượng Krong Ana & 10 & 230,8 & 9 & Thượng Srê Pốk & 40 & 537,9 \\
\hline & & 11 & 198 & & & 41 & 70,5 \\
\hline & & 12 & 24,8 & & & 42 & 119,5 \\
\hline & & 13 & 51,7 & & & 43 & 150,9 \\
\hline & & 14 & 564,9 & & & 45 & 212,8 \\
\hline & & 15 & 18,6 & & & 46 & 12,8 \\
\hline & & 16 & 27,1 & & & 47 & 251,5 \\
\hline & & 17 & 489,1 & & & 48 & 104,4 \\
\hline & & 18 & 698,3 & & & 49 & 90,4 \\
\hline & & 21 & 93,8 & & & 50 & 334,3 \\
\hline & & 22 & 21,4 & & & 51 & 124,9 \\
\hline & & 24 & 362,3 & & & 52 & 56,8 \\
\hline \multirow[t]{6}{*}{6} & Hạ Krong Ana & 19 & 11,7 & & & 55 & 107,2 \\
\hline & & 20 & 20,2 & & & 56 & 322,6 \\
\hline & & 23 & 11,3 & 10 & Hạ Srê Pốk & 53 & 77,3 \\
\hline & & 24 & 323,9 & & & 54 & 297,5 \\
\hline & & 34 & 79,3 & & & 56 & 117,4 \\
\hline & & 35 & 109,8 & & & 57 & 899,3 \\
\hline
\end{tabular}




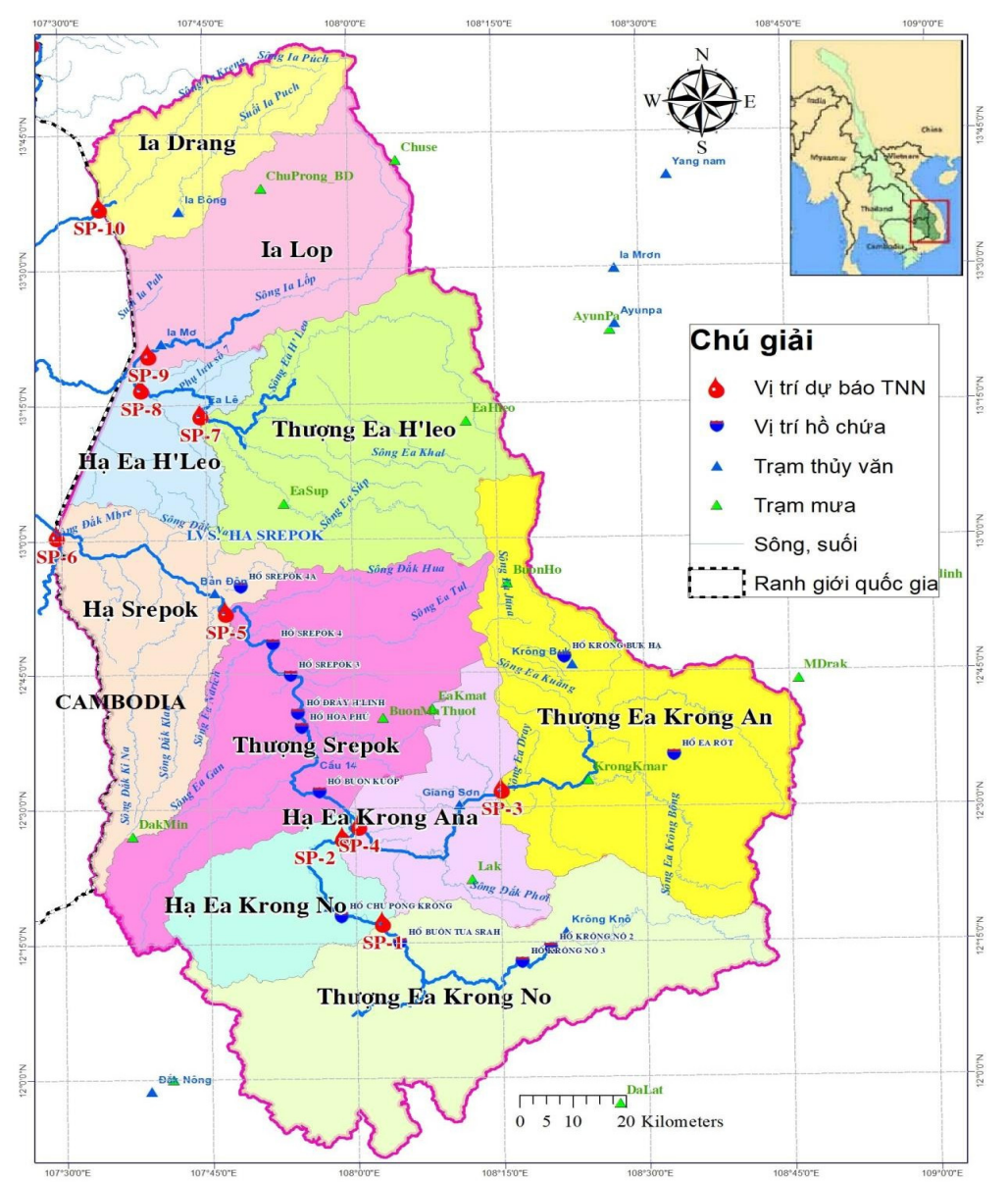

Hình 3. Bản đồ phân chia tiểu lưu vực sông Srê Pốk.

\subsection{Một số phương pháp tính toán các chỉ số đánh giá số lượng tài nguyên nước}

\subsubsection{Chỉ số Falkenmark}

Chỉ số Falkenmark là chỉ số phổ biến nhất trên thế giới để đánh giá tình trạng căng thẳng về nước. Chỉ số được định nghĩa là tổng lượng dòng chảy năm đáp ứng nhu cầu sử dụng của con người. Chỉ số này thường được sử dụng trong đánh giá trên phạm vi quốc gia khi mà dữ liệu có sẵn nhằm cung cấp kết quả trực quan và dễ hiểu. Dựa trên việc sử dụng bình quân đầu người, các điều kiện nước trong một khu vực có thể được phân loại như: không căng thẳng, căng thẳng, khan hiếm và cực kì khan hiếm (Bảng 2) [14].

Bảng 2. Cấp độ căng thẳng tài nguyên nước theo chỉ số Falkenmark.

\begin{tabular}{cc}
\hline Chỉ số (mª̂̀̀ người) & Tình trạng \\
\hline$>1700$ & Không căng thẳng \\
$1000-1700$ & Căng thẳng \\
$500-1000$ & Khan hiếm \\
$<500$ & Cực kỳ khan hiếm \\
\hline
\end{tabular}

\subsubsection{Chỉ số căng thẳng tài nguyên nước WSI}

Chỉ số WSI được định nghĩa là khoảng thiếu hụt tương đối giữa giá trị thực tế và ngưỡng tương ứng của mỗi chỉ số căng thẳng. WSI là giá trị trung bình có trọng số của các chỉ số WSIP, WSIE và WSID và được tính theo công thức: 


$$
\mathrm{WSI}_{\mathrm{j}}=\sum_{\mathrm{i}=1}^{\mathrm{n}} \rho_{\mathrm{i}} \mathrm{WSI}_{\mathrm{ij}}
$$

Trong đó $W_{S I}$ là chỉ số căng thẳng tài nguyên nước tổng hợp của vùng $\mathrm{j}$; $\rho_{\mathrm{i}}$ là trọng số của mỗi chỉ số căng thẳng tài nguyên nước thành phần; WSIP là chỉ số căng thẳng tài nguyên nước tính theo dân số; WSIE là chỉ số căng thẳng nước tính theo môi trường sinh thái; WSID là chỉ số căng thẳng nước tính theo phát triển kinh tế.

Khi WSI $I_{i j}<0$ nghĩa là không có căng thẳng về nước ở vùng j về mặt chỉ số i. Hiển nhiên chỉ số căng thẳng tài nguyên nước tổng hợp $\mathrm{WSI}_{\mathrm{j}}$ sẽ nằm trong khoảng $0<1$. Giá trị $\mathrm{WSI}_{\mathrm{j}}$ càng lớn thì sự thiếu hụt nước càng nghiêm trọng. Cũng giống như chỉ số Falkenmark, WSI chưa tính đến chất lượng nước [18].

\subsubsection{Chỉ số khan hiếm nước RWS}

Đây là chỉ số hàm chứa thông tin về tiềm năng nguồn nước có sẵn. Nó được xác định bởi tỉ lệ sử dụng nước hàng năm so với tổng lượng nước ngọt sẵn có, có thể xem như tỉ lệ phần trăm của tổng số năng lượng tái tạo tài nguyên nước hoặc là tỉ lệ phần trăm tài nguyên nước nội địa đã đưa vào biến nước khử muối để xác định tài nguyên nước mặn [16]. Việc sử dụng biến nước khử muối là không đáng kể trên quy mô toàn cầu, nhưng nó là rất quan trọng ở một số vùng, như ví dụ ở các tiểu Vương quốc Ả Rập thống nhất, nơi nước khử muối chiếm $18 \%$ nước hàng năm. Chỉ tiêu này được xác định bằng tỉ lệ:

$$
\mathrm{R}_{\mathrm{wS}}=\frac{\mathrm{W}-\mathrm{S}}{\mathrm{Q}}
$$

Trong đó Rws là chỉ số khan hiếm nước; W là lượng nước ngọt sử dụng hàng năm; $\mathrm{S}$ là lượng nước khử muối; $\mathrm{Q}$ là lượng nước có sẵn hàng năm được tính theo công thức:

$$
\mathrm{Q}=\mathrm{R}+\alpha \sum \mathrm{D}_{\mathrm{UP}}
$$

Trong đó $\mathrm{R}$ là lượng tài nguyên nước nội địa; Dup là tổng lượng tài nguyên nước từ bên ngoài chảy vào trong nước và $\alpha$ là là tỉ lệ của tài nguyên nước bên ngoài mà có thể được sử dụng. Các yếu tố $\alpha$ chịu ảnh hưởng bởi chất lượng của các nước xuyên biên giới, tiêu thụ thực tế của tài nguyên nước trong khu vực thượng nguồn và khả năng tiếp cận của các nước.

Các mức độ nghiêm trọng của áp lực về nước được phân loại như sau: (1) RWS $<0,1$ : Không có áp lực về nước; (2) $0,1<\mathrm{RWS}<0,2$ : Áp lực thấp; (3) $0,2<\mathrm{RWS}<0,4$ : Áp lực vừa phải; (4) 0,4<RWS: Áp lực cao [18].

\subsubsection{Chỉ số sức ép khai thác, sử dụng nguồn nước DPS}

Khai thác quá mức nguồn nước sẽ làm ảnh hưởng đến quá trình thủy văn và khả năng tái tạo của nguồn nước. Do đó, hệ số khai thác nguồn nước, được xác định tỉ lệ phần trăm nhu cầu sử dụng nước so với tổng lượng nước có sẵn trong tự nhiên:

$$
\mathrm{PS}=\frac{\mathrm{W}_{\mathrm{u}}}{\mathrm{W}}
$$

Trong đó $\mathrm{Wu}$ là tổng nhu cầu nước cho các ngành trên toàn lưu vực $\left(\mathrm{m}^{3}\right) ; \mathrm{W}$ là tổng lượng nước tự nhiên trên toàn lưu vực $\left(\mathrm{m}^{3}\right)$.

Nếu DPs $=20 \%$ : Mức căng thẳng vẫn nằm trong giới hạn khai thác sử dụng. DPs trong khoảng 30-40\% là mức căng thẳng cao [18].

Để hoàn thiện công tác cảnh báo, dự báo, cũng như thực hiện tốt công tác quản lý, khai thác bền vững tài nguyên nước cần tính toán được chỉ số căng thẳng trong khai thác, sử dụng tài nguyên nước DPS, nghiên cứu đề xuất 3 cấp độ cảnh báo của chỉ số căng thẳng trong khai thác, sử dụng tài nguyên nước cho LVS Srê Pốk như sau: (1) DPs $\leq 20 \%$ : căng thẳng thấp; (2) $20 \%<\mathrm{DPs}<40 \%$ là mức căng thẳng trung bình; (3) DPs $\geq 40 \%$ là mức căng thẳng cao. Để đánh giá chất lượng nước mặt LVS Srê Pốk nghiên cứu sử dụng chỉ số WQI với các cấp độ được thống kê trong Bảng 3. 
Bảng 3. Đánh giá chất lượng nước theo chỉ số WQI.

\begin{tabular}{|c|c|c|c|c|}
\hline $\begin{array}{l}\text { Giá trị } \\
\text { WQI }\end{array}$ & $\begin{array}{l}\text { Chất lượng } \\
\text { nước }\end{array}$ & Phù hợp với mục đích sử dụng & Màu & Hiển thị \\
\hline $91-100$ & Rất tốt & $\begin{array}{l}\text { Sử dụng tốt cho mục đích cấp nước sinh } \\
\text { hoạt }\end{array}$ & $\begin{array}{l}\text { Xanh } \\
\text { biển }\end{array}$ & \\
\hline $76-90$ & Tốt & $\begin{array}{l}\text { Sử dụng cho mục đích cấp nước sinh hoạt } \\
\text { nhưng cần các biện pháp xử lý phù hợp }\end{array}$ & Xanh lá cây & \\
\hline $51-75$ & Trung bình & $\begin{array}{l}\text { Sử dụng cho mục đích tưới tiêu và các } \\
\text { mục đích tương đương khác }\end{array}$ & Vàng & \\
\hline $26-50$ & Kém & $\begin{array}{l}\text { Sử dụng cho giao thông thủy và các mục } \\
\text { đích tương đương khác }\end{array}$ & Da cam & \\
\hline $10-25$ & Ô nhiễm nặng & $\begin{array}{l}\text { Nước ô nhiễm nặng, cần các biện pháp xử } \\
\text { lý trong tương lai }\end{array}$ & Đỏ & \\
\hline$<10$ & $\begin{array}{l}\text { Ô nhiễm rất } \\
\text { nặng }\end{array}$ & $\begin{array}{l}\text { Nước nhiễm độc, cần có biện pháp khắc } \\
\text { phục, xử lý }\end{array}$ & Nâu & \\
\hline
\end{tabular}

\subsection{Phương pháp tính các chỉ số đánh giá chất lương tài nguyên nước (WQI)}

Chỉ số đánh giá chất lượng nước WQI được tính toán theo hướng dẫn trong Quyết định số 879/QĐ-TCMT ngày 01 tháng 7 năm 2011 của Tổng cục Môi trường về ban hành sổ tay hướng dẫn tính toán chỉ số chất lượng nước.

$$
\mathrm{WQI}_{\mathrm{SI}}=\frac{\mathrm{q}_{\mathrm{i}}-\mathrm{q}_{\mathrm{i}+1}}{\mathrm{BP}_{\mathrm{i}+1}-\mathrm{BP}_{\mathrm{i}}}\left(\mathrm{BP}_{\mathrm{i}+1}-\mathrm{C}_{\mathrm{p}}\right)+\mathrm{q}_{\mathrm{i}+1}
$$

Trong đó $\mathrm{BP}_{\mathrm{i}}$ là nồng độ giới hạn dưới của giá trị thông số quan trắc được quy định trong Bảng 3 tương ứng với mức $\mathrm{i} ; \mathrm{BP}_{\mathrm{i}+1}$ là nồng độ giới hạn trên của giá trị thông số quan trắc được quy định trong Bảng 3 tương ứng với mức $\mathrm{i}+1$; $\mathrm{q}_{\mathrm{i}}$ là giá trị WQI ở mức $\mathrm{i}$ đã cho trong bảng tương ứng với giá trị $B P_{\mathrm{i}} ; \mathrm{q}_{\mathrm{i}+1}$ là giá trị $\mathrm{WQI}$ ở mức $\mathrm{i}+1$ cho trong bảng tương ứng với giá trị $\mathrm{BP}_{\mathrm{i}+1} ; \mathrm{C}_{\mathrm{p}}$ là giá trị của thông số quan trắc được đưa vào tính toán.

Bảng 1. Bảng quy định giá trị qi và Bpi.

\begin{tabular}{|c|c|c|c|c|c|c|c|c|c|c|}
\hline \multirow{3}{*}{$\mathbf{i}$} & \multirow{3}{*}{$\mathbf{q}_{\mathrm{i}}$} & \multirow{3}{*}{ BOD5 } & \multicolumn{8}{|c|}{ Giá trị $B P_{i}$ quy định đối với từng thông số } \\
\hline & & & COD & $\mathbf{T}^{\circ} \mathrm{C}$ & $\mathbf{N}-\mathrm{NH}_{4}$ & $\mathrm{~N}-\mathrm{NO}_{3}$ & $\mathrm{~N}-\mathrm{NO}_{2}$ & $\mathbf{P}-\mathrm{PO}_{4}$ & Coliform & E.coli \\
\hline & & & \multicolumn{6}{|c|}{$\mathrm{mg} / \mathrm{L}$} & \multicolumn{2}{|c|}{ MPN/100 mL } \\
\hline 1 & 100 & $\leq 4$ & $\leq 10$ & $\leq 4$ & $<0,3$ & $\leq 2$ & $\leq 0,05$ & $\leq 0,1$ & $\leq 2.500$ & $\leq 20$ \\
\hline 2 & 75 & 6 & 15 & 6 & 0,3 & 5 & - & 0,2 & 5.000 & 50 \\
\hline 3 & 50 & 15 & 30 & 15 & 0,6 & 10 & - & 0,3 & 7.500 & 100 \\
\hline 4 & 25 & 25 & 50 & 25 & 0,9 & 15 & - & 0,5 & 10.000 & 200 \\
\hline 5 & 10 & $\geq 50$ & $\geq 150$ & $\geq 50$ & $\geq 5$ & $\geq 15$ & $\geq 0,05$ & $\geq 4$ & $>10.000$ & $>200$ \\
\hline
\end{tabular}

Sau khi tính toán WQI đối với từng thông số trên, việc tính toán WQI được áp dụng như sau:

$$
\mathrm{WQI}=\frac{\mathrm{WQI}_{\mathrm{pH}}}{100}\left[\frac{1}{5} \sum_{\mathrm{a}=1}^{5} \mathrm{WQI}_{\mathrm{a}} \mathrm{x} \frac{1}{2} \sum_{\mathrm{b}=1}^{2} \mathrm{WQI}_{\mathrm{b}} \mathrm{xWQI}\right]^{1 / 3}
$$

Trong đó $\mathrm{WQI}_{\mathrm{a}}$ là giá trị $\mathrm{WQI}$ đã tính toán đối với 5 thông số: $\mathrm{DO}, \mathrm{BOD}_{5}, \mathrm{COD}, \mathrm{N}-$ $\mathrm{NH}_{4}, \mathrm{P}-\mathrm{PO}_{4}$; $\mathrm{WQI}_{\mathrm{b}}$ là giá trị WQI đã tính toán với 2 thông số: TSS, độ đục; $\mathrm{WQI}$ là giá trị WQI đã tính toán với thông số Tổng Coliform; $\mathrm{WQI}_{\mathrm{pH}}$ là giá trị WQI đã tính toán với thông số $\mathrm{pH}$. 


\section{Kết quả và thảo luận}

3.1. Kết quả tính toán đánh giá số lương tài nguyên nuớc mặt LVS Srê Pốk theo chỉ số $\operatorname{PDs}(12 / 2020)$

Khả năng khai thác được tính toán dựa trên nhu cầu sử dụng và lượng nước có thể khai thác sử dụng. Trong tháng 12 năm 2020, trên lưu vực sông Srê Pốk có 9 tiểu vùng thuộc chỉ số căng thẳng thấp, 01 tiểu vùng ở mức căng thẳng trung bình. Kết quả tính toán chỉ số PDs tương ứng với các cấp cảnh báo của 9 tiểu vùng được thể hiện trên hình 4.

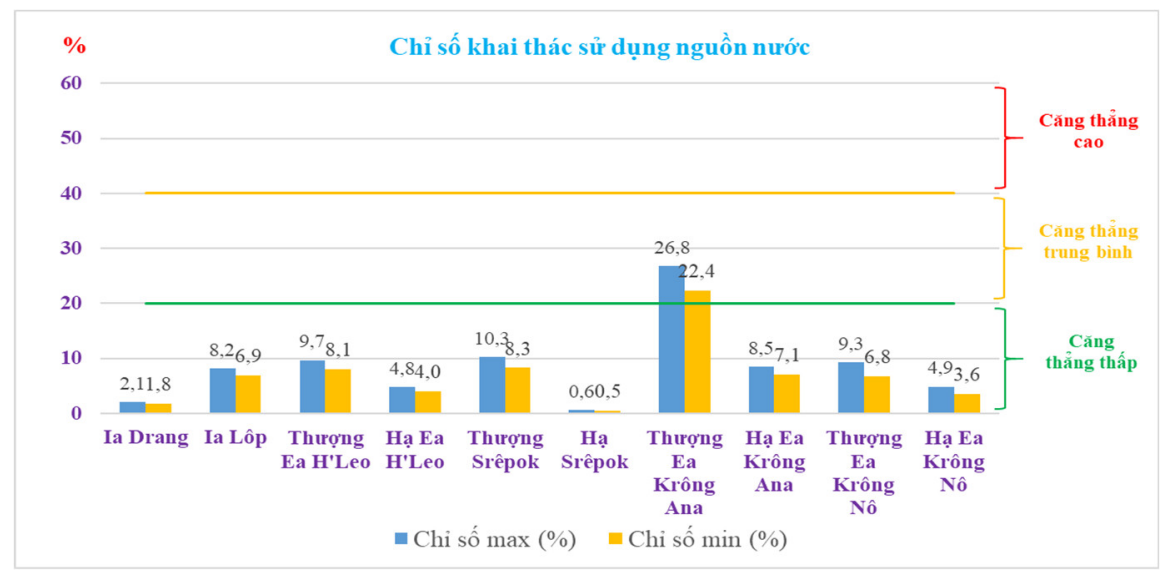

Hình 4. Cảnh báo ngưỡng căng thẳng nguồn nước trên các tiểu vùng thuộc lưu vực sông Srê Pốk.

Dựa trên nhu cầu sử dụng nước thực tế của các ngành sử dụng nước (sinh hoạt, nông nghiệp, công nghiệp, thủy sản, chăn nuôi, du lịch và môi trường), tổng lượng nước đến dự báo và thông tin khai thác sử dụng nước dưới đất, trong tháng 12 năm 2020, trên lưu vực sông Srê Pốk có 4 vùng dự báo có nguy cơ thiếu nước, với tổng lượng nước thiếu từ 0,232 đến 0,696 triệu $\mathrm{m}^{3}$ (Bảng 5).

Bảng 2. Cảnh báo lượng nước thiếu trong tháng 12 năm $2020\left(10^{6} \mathrm{~m}^{3}\right)$.

\begin{tabular}{cllcccc}
\hline TT & Vùng cảnh báo & \multirow{2}{*}{ Sông } & \multicolumn{2}{c}{ Lượng nước thiếu } & \multicolumn{2}{c}{$\%$ thiếu nước } \\
\cline { 3 - 7 } & & & Tù̀ & Đến & Tù̀ & Đến \\
\hline 1 & Thượng Ea H'leo & Ea H’leo & 0,065 & 0,195 & 0,50 & 1,50 \\
2 & Thượng Ea Krong Ana & Krông Ana & 0,043 & 0,128 & 0,08 & 0,23 \\
3 & Hạ Ea Krong Ana & Krông Ana & 0,059 & 0,176 & 0,26 & 0,79 \\
4 & Thượng Srê Pốk & Srê pôk & 0,066 & 0,198 & 0,33 & 0,98 \\
\hline
\end{tabular}

3.2. Kết quả tính toán đánh giá chất lượng tài nguyên nước mặt LVS Srê Pốk theo chỉ số WQI (Qúy I/2021)

Kết quả phân tích chất lượng nước sông quý I/2021 được trình bày trong bảng 6 . Trong đó, chất lượng nước tháng 1/2021 tính theo chỉ số WQI cho thấy chất lượng nước sông Srê Pốk rất tốt có thể sử dụng cho mục đích cấp nước sinh hoạt, chất lượng nước tháng 3 có thể sử dụng cho mục đích cấp nước sinh hoạt nhưng cần các biện pháp xử lý phù hợp. Tuy nhiên, tháng 2/2021 do chỉ sổ DO, Coliform và Ecoli hạ thấp dẫn tới chất lượng nước đánh giá theo WQI kém chỉ sử dụng được cho giao thông thủy và các mục đích tương đương khác.

Bảng 3. Kết quả đánh giá chất lượng nước sông quý I/2021 theo chỉ số WQI tại trạm Đức Xuyên.

\begin{tabular}{|c|c|c|c|c|c|c|c|c|c|c|c|c|c|c|c|c|c|c|c|}
\hline \multirow{2}{*}{\multicolumn{2}{|c|}{ STT Ngày phân tích }} & \multicolumn{17}{|c|}{ Các chỉ tiêu phân tích } & \multirow{2}{*}{ WQI } \\
\hline & & $\mathrm{pH}$ & As & $\mathrm{Cd}$ & $\mathrm{Pb}$ & Cr6t & $\mathrm{Cu}$ & $\mathrm{Zn}$ & $\mathrm{Hg}$ & D0 & $\mathrm{BOD}_{5}$ & COD & $\mathrm{NH}_{4}^{+}$ & $\mathrm{NO}_{3}^{\circ}$ & $\mathrm{NO}_{2}^{\circ}$ & $\mathrm{PO}_{4}^{3-}$ & Coliform & E. Coli & \\
\hline 1 & $15 / 01 / 2021$ & 100 & 100 & 100 & 100 & 100 & 100 & 100 & 100 & 92 & 100 & 100 & 100 & 100 & 100 & 100 & 89 & 88 & 93 \\
\hline 2 & 15/02/2021 & 100 & 100 & 100 & 100 & 100 & 100 & 100 & 100 & 71 & 100 & 100 & 100 & 100 & 100 & 100 & 10 & 10 & 31 \\
\hline 3 & $15 / 3 / 2021$ & 100 & 100 & 100 & 100 & 100 & 100 & 100 & 100 & 100 & 100 & 100 & 100 & 100 & 100 & 100 & 100 & 54 & 88 \\
\hline
\end{tabular}




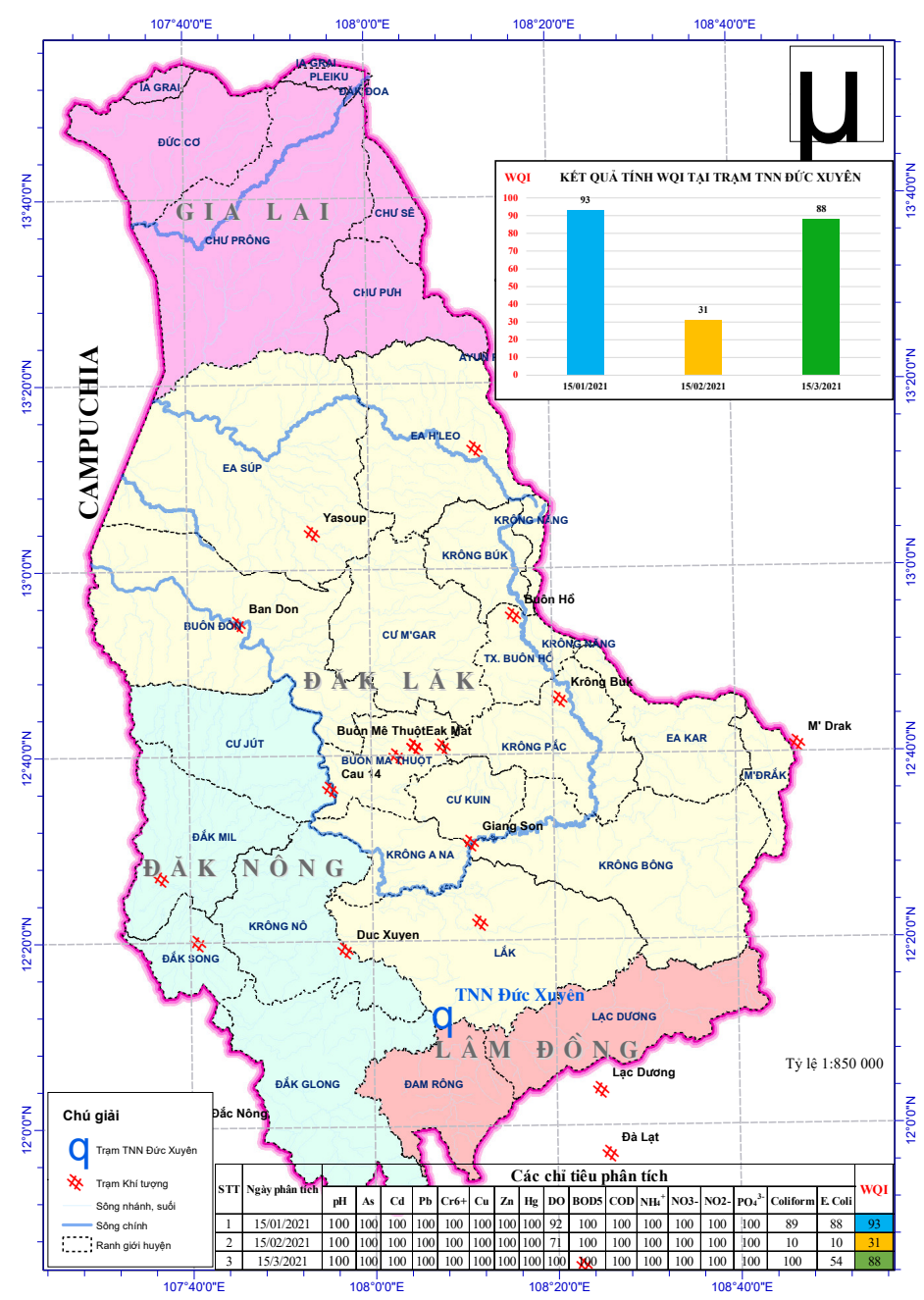

Hình 5. Bản đồ chất lượng nước quý I/2021 theo chỉ số WQI tại trạm Đức Xuyên.

\section{Kết luận}

Bài báo đã tiến hành nghiên cứu tổng quan và phương pháp tính toán các chỉ số đánh giá số lượng và chất lượng tài nguyên nước hiện có: chỉ số Falkenmark, chỉ số căng thẳng nước WSI, chỉ số khan hiếm nước Rws, chỉ số WQI... Trên cơ sở đó lựa chọn chỉ số PDs áp dụng tính toán đánh giá số lượng và chỉ số WQI để đánh giá chất lượng nước mặt cho các tiểu lưu vực trên LVS Srê Pốk, phục vụ công tác cảnh báo dự báo tài nguyên nước trên lưu vực.

Kết quả tính toán đánh giá số lượng tài nguyên nước mặt LVS Srê Pốk theo chỉ số PDs cho thấy, trong tháng 12 năm 2020, trên lưu vực sông Srê Pốk có 9 tiểu vùng thuộc ngưỡng căng thẳng thấp với $\mathrm{PDs}<20 \%$, tiểu vùng thượng EaKrong Ana ở mức căng thẳng trung bình với PDs nằm trong khoảng 22,4-28,6\%.

Kết quả tính toán đánh giá chất lượng nước quý I/2021 theo chỉ số WQI với 17 thông số quan trắc cho $\mathrm{WQI}_{\text {tháng } 1}=93$ cho thấy chất lượng nước sông Srê Pốk tháng $1 / 2021$ rất tốt, có thể đáp ứng cho mục đích sinh hoạt; với $\mathrm{WQI}_{\text {tháng } 3}=88$ cho thấy chất lượng nước tháng 3/2021 đạt loại tốt có thể sử dụng cho mục đích cấp nước sinh hoạt nhưng cần các biện pháp xử lý phù hợp. Tháng 2/2021 do chỉ sổ DO, Coliform và Ecoli hạ thấp dẫn tới chất lượng nước đánh giá theo WQI kém với $\mathrm{WQI}_{\text {tháng } 2}=31$ chỉ sử dụng được cho giao thông thủy và các mục đích tương đương khác.

Kết quả nghiên cứu đánh giá tài nguyên nước mặt lưu vực sông Srê Pốk thông qua các chỉ số về số lượng và chất lượng đã cho thấy tình trạng và mức độ căng thẳng nguồn nước trên 10 tiểu lưu vực sẽ là nguồn thông tin dữ liệu quan trọng, làm cơ sở phục vụ công tác dự báo, cảnh báo tài nguyên nước cũng như đề xuất xây dựng chính sách quản lý, quy hoạch 
khai thác sử dụng và phát triển bền vững lưu vực sông Srê Pốk hiện tại cũng như trong trong tương lai. Tuy nhiên, để nâng cao chất lượng kết quả tính toán các chỉ số căng thẳng cần đảm bảo độ tin cậy ngay từ bước tính toán dự báo tài nguyên nước cũng như hạn chế sai số quan trắc, phân tích chất lượng nước. Hơn hết, đối với một số vùng trên lưu vực sông Srê Pốk, việc khai thác sử dụng tài nguyên nước dưới đất khá phổ biến, nhưng khi tính toán dự báo lại chưa tích hợp giữa tài nguyên nước mặt và nước dưới đất dẫn đến sai số trong quá trình tính toán dự báo, cảnh báo mức độ căng thẳng. Do vậy, cần nghiên cứu tích hợp giữa nguồn tài nguyên nước mặt và nước dưới đất để nâng cao chất lượng dự báo, cảnh báo tài nguyên nước trong tương lai.

Đóng góp của tác giả: Xây dựng ý tưởng nghiên cứu: L.T.M.V., B.T.B.N.; Lựa chọn phương pháp nghiên cứu: L.V.M.V., B.T.B.N., T.V.H., L.T.T.; Thu thập, phân tích, tính toán xử lý số liệu: B.T.B.N., T.V.H, L.T.T.; Viết bản thảo bài báo: B.T.B.N., L.T.M.V., D.Q.T.; Chỉnh sửa bài báo: B.T.B.N., L.T.M.V., D.Q.T.

Lò̀i cảm ơn: Bài báo được hoàn thành dựa trên kết quả nghiên cứu đề tài cấp bộ "Nghiên cứu cơ sở khoa học và thực tiễn nhằm đề xuất bổ sung, hoàn thiện quy định về cảnh báo, dự báo TNN", mã số TNMT.2018.02.06.

Lời cam đoan: Tập thể tác giả cam đoan bài báo này là công trình nghiên cứu của tập thể tác giả, chưa được công bố ở đâu, không được sao chép từ những nghiên cứu trước đây; không có sự tranh chấp lợi ích trong nhóm tác giả.

\section{Tài liệu tham khảo}

1. Cư, N.V.; Sơn, N.H. Phát triển bền vững tài nguyên và môi trương nước lưu vực sông Hương tỉnh Thừa Thiên Huế. Tạp chi khoa học, Đại học Huế 2009, 50, 17-26.

2. Bích, Đ.T.N.; Đơn, N.C. Phân bổ hợp lý tài nguyên nước lưu vực sông Srepok. Tạp chi Khí tuợng Thủy văn 2019, 703, 60-68.

3. Phú, H. Phát triển bền vững tài nguyên nước lưu vực sông Serepok. Tạp chi Khí tuợng Thủy văn 2019, 708, 13-22.

4. Minh, N.H.; Vân, T.T.; Vinh, L.T.; Thái, H.T. Đánh giá tác động của biến đổi khí hậu đến tài nguyên nước lưu vực sông Lô. Tạp chi Khí tượng Thủy văn 2015, 651, 3-8.

5. Hoàng, L.V.; Thăng, L.V.; Hoàng, H.Đ.T. Tài nguyên nước mặt vùng đồng bằng ven biển tỉnh Quảng Nam trong bối cảnh của biến đổi khí hậu. Khoa học và công nghệ, kinh tế sinh thái 2011, 40, 128-133.

6. Hiếu, B.Đ.; Hương, H.T.L.; Liễu, N.T.; Thịnh, Đ.Q.; Diệp, B.N. Nghiên cứu đánh giá rủi ro đến tài nguyên nước mặt do biến đổi khí hậu: Áp dụng cho tỉnh Quảng Ngãi. Tạp chí Khí tương Thủy văn 2020, 711, 1-13.

7. Wichakul, S.; Tachikawa, Y.; Shiiba, M.; Yorozu, K. Developing a regional distributed hydrological model for water resources assessment and its application to the Chao Phraya River Basin. J. Japan Soc. Civ. Eng. Ser B1 (Hydraulic Engineering) 2013, 69(4), I_43-I_48. https://doi.org/10.2208/jscejhe.69.I_43.

8. Dessu, S.B.; Melesse, A.M.; Bhat, M.G.; McClain, M.E. Assessment of water resources availability and demand in the Mara River Basin. Catena 2014, 115, 104114. https://doi.org/10.1016/j.catena.2013.11.017.

9. Metobwa, O.G.M.; Mourad, K.A.; Ribbe, L. Water Demand Simulation Using WEAP 21: A Case Study of the Mara River Basin, Kenya. Int. J. Nat. Resour. Ecol. Manage. 2018, 3(1), 9-18.

10. Dessu, S.B.; Melesse, A.M.; Bhat, M.G.; Price, R.M.; Seid, A.H.; Debede, S.A.; McClain, M.E. Development and application of a priority rated optimization model (PROM) for multi-sector water resource management systems. Environ. Modell. Software 2019, 113, 84-97. https://doi.org/10.1016/j.envsoft.2018.11.014. 
11. Young, W.A.; Harshadeep, N.R. Managing Water Resources in Large River Basins. Water 2020, 12(12), 3486. https://doi.org/10.3390/w12123486.

12. Yan, J.; Jia, S.; Lv, A.; Zhu, W. Water Resources Assessment of China's Transboundary River Basins Using a Machine Learning Approach. Water Resour. Res. 2018, 55(1), 632-655. https://doi.org/10.1029/2018WR023044.

13. Trang, P.T.T.; Hương, H.T.L.; Đại, N.V.; Thủy, N.H. Một số phương pháp xác định chỉ số căng thẳng tài nguyên nước và bước đầu áp dụng cho vùng Nam Trung Bộ. Tạp chí Khi tương Thủy văn 2014, 644, 20-21.

14. Hà, N.N.; Giang, N.T.; Trình, N.M. Chỉ số tài nguyên nước mặt lưu vực sông Vệ, Tạp chí Khoa học ĐHQGHN: Các Khoa học Trái đất và Môi truờng 2016, 32(3S), 67-76.

15. Phú, H.T. Nghiên cứu xây dựng phần mềm tính toán chỉ số chất lượng nước WQI cho lưu vực sông Srêpok. Tạp chi Khí tượng Thủy văn 2019, 702, 31-40.

16. Nghiên cứu và báo cáo của Daniel Constable, Các lưu vực sông Sê San và Srê Pốk, 2015.

17. Báo cáo thuyết minh quy hoạch tài nguyên nước lưu vực sông Sê San - Srê Pốk . Dự án Quản lý tổng hợp Tài nguyên nước Mê Công, 2020.

18. Brown, A.; Matlock, M.D. A Review of Water Scarcity Indices and Methodologies. White paper No. 106, University of Arkansas, The Sustainability Consortium, 2011.

\title{
Research on calculating surface water resource assessment index for warning and forecasting of water resources: Case study on the Srepok River basin
}

\section{Le Thi Mai Van ${ }^{1 *}$, Bui Thi Bich Ngoc ${ }^{1}$, Doan Quang Tri ${ }^{2}$, Truong Van Hung ${ }^{1}$, Le The Trung ${ }^{1}$}

${ }^{1}$ National Center for Water Resources Planning and Investigation;

lethimaivantnn@gmail.com; bichngoc209hunre@gmail.com; lethetrung.tnmt@gmail.com

${ }^{2}$ Vietnam Journal of Hydrometeorology, Viet Nam Meteorological and Hydrological Administration; doanquangtrikttv@gmail.com

\begin{abstract}
The study evaluated the quantity and quality of water to forecast the risk of shortage and decline of water resources. This study applied several methods to calculate the surface water indicators: quantitative evaluation index and surface water quality assessment index for the Srepok River basin. The results of experimental calculation and assessment of surface water resources in the basin in December 2020 showed that in 9 sub-regions with low index, there was 1 sub-region with a medium result. The quality of water in January 2021 which calculated according to the WQI index shows that the water quality of the Srepok River was very good and can be used for domestic water supply purposes, the water quality calculated in March can be used for domestic water supply purposes but it needed proper treatments. However, the WQI of February 2021 showed poor results and could only be used for navigation and other equivalent purposes. The set of indicators was applied to calculate and assess surface water resources to serve the warning and forecast of water resources for all levels of management and to improve the practicality of warning and forecast bulletins to users.
\end{abstract}

Keywords: Water resource assessment index; Stress; News; Srepok. 